\title{
Urban energy harvest and optimisation in use of renewable energy sources in the Droevendaal residential area
}

\author{
G. V. Tragopoulos ${ }^{1}$, W. Timmermans ${ }^{2} \&$ R. Rovers ${ }^{3}$ \\ ${ }^{1}$ Alterra Green World Research; Urban Rural Group, The Netherlands \\ ${ }^{2}$ Van Hall Larenstein University of Professional Education, \\ Wageningen UR, The Netherlands \\ ${ }^{3}$ Urban Environment Group, Wageningen UR, The Netherlands
}

\begin{abstract}
Contemporary societies are characterized by the improvident exploitation of energy sources, under the context of economic development. The latter in the form that we address it nowadays, has been started, simultaneously, with the triggering of the industrial revolution. Moreover it is known that the countries that hold the fossil fuels' sources are a few, while the appetite for energy is growing after the opening of the huge Asian market. The consequences of the aforementioned issues are multidimensional, as far as the growing environmental burden and the geopolitical status quo are concerned. Thus, could be stated that is a time for a shift to "clean" energy production technologies, which could be addressed as the renewable energy sources. The latter created the idea of urban energy harvest as a matter of a more general concept towards to sustainable societies. The main visions, concerning the energy harvest concept is not only to produce energy by renewable and environmental friendly sources, but also to transform the urban areas from energy consumers to energy producers, ensuring in this way the energy autonomy and the geopolitical independence of every country.
\end{abstract}

Keywords: urban energy harvest, sustainable societies, energy autonomy, optimum energy combination.

\section{Introduction}

Droevendaal is a student residential site in the outskirts of the Wageningen Municipal area. The site surface is about 5ha and consists of 33 houses, which 
host about 198 persons and could be characterized as a rather small rural system. The annual energy demands of the area come up to $1.003 .977 \mathrm{KWh} / \mathrm{year}$. Thus, Droevendaal can be characterized as another energy consumerist human settlement. Then the question that derives is "Can human settlements be transformed from energy consumers to energy producers"?

The answer in this question is that they actually can, if only the people would consider the energy from another aspect angle. If the people would consider their living sites as energy production sites and if they would shift from fossil fuel consumption to renewable energy sources, following the principles of "Trias Energetica" then it would be possible a shift from energy consuming settlements to energy producing settlements. In this study it will be attempted an approach to those elements that have the potential to produce that amount of energy, which not only is able to cover the energy needs in a local level, but also is able to create that positive equilibrium in order to switch The Droevendaal area to an energy production site.

\section{Methodology}

In order to achieve our aims for the creation of an energy productive area, three dominant renewable sources of energy were considered for use, with respect to solar, wind and biomass energy sources. Moreover, willing to create a common line between the three different energy concepts we used a common indicator, which was the available surface of both Droevendaal built up and non-built up area, but also different indicators of the same nature such as the wind speed, the solar irradiation and the amount of biomass as much as its calorific value. Thereafter, we homogenized all the different units in one, aiming to assess the total energy production of our concepts and make it comparable (KWh/capita.year). Furthermore, the three developed concepts were combined in three different scenarios concerning "The maximum energy harvest", "The social sustainability" and "The cost efficiency". Finally we ranked the aforementioned scenarios, using criteria such as, the energy production, the level of energy autonomy of the area, the environmental performance, the energy production costs, the level of land use and the degradation level of the local landscape aesthetics.

\section{The concepts}

There are three concepts that have been developed under the context of the present study and which are analysed in the following paragraphs.

\subsection{The solar concept}

The solar harvest concept of the Droevendaal area incorporates three different options, concerning the exploitation of solar energy. The concept includes PV panels, solar heaters and road energy systems, regarding the production of electricity hot water and heating respectively.

In order to determine the total energy production of the solar concept is viable to assess primarily the potential solar energy that can be harvested from the 
Droevendaal area. The horizontal solar irradiation in Wageningen area is 2656 $\mathrm{Wh} / \mathrm{m}^{2}$.day [1]. Moreover, the average horizontal solar irradiation of Wageningen regarding the entire year is $970 \mathrm{KWh} / \mathrm{m}^{2}$.year. Based on this data, the potential solar energy production of the Droevendaal area is about 49GWh/year. The realistic energy production of the site taking under consideration the aforementioned concepts will be ranging from 2.868.0113.290.312KWh/year $(2,9-3,3 G W h / y e a r)$. The following graph illustrates the comparison between the energy production of the solar concept and the current energy consumption in Droevendaal.

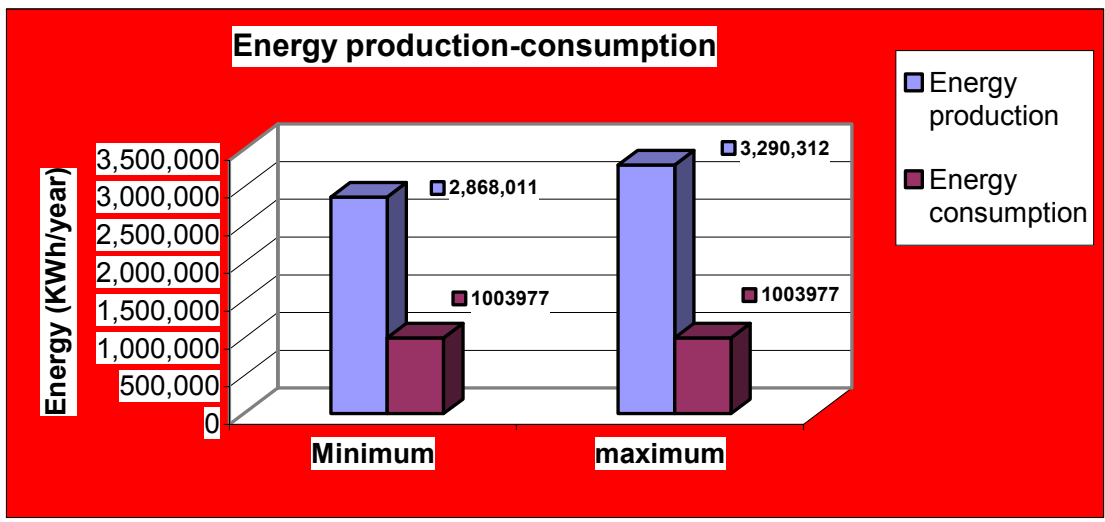

Figure 1: Comparison between the energy production of the solar concept and the energy consumption of the Droevendaal area.

\subsection{The wind concept}

The wind harvest concept of the Droevendaal area incorporates the use of wind turbines for the production of electricity. In order to determine the total energy production, concerning the wind concept, it is viable to determine the potential wind harvest in the Droevendaal area. The latter regards the wind energy content and has been considered for three different heights as is depicted in the following table.

Moreover the realistic wind harvest of Droevendaal site has been considered for the aforementioned heights, with respect to different types of wind turbines. Thus, the realistic wind harvest is ranging from $557.112 \mathbf{K W h} / \mathbf{y e a r}$ in $30 \mathrm{~m}$ heights to $\mathbf{3 . 5 1 3 . 3 1 4 K W h / y e a r ~ i n ~} 100 \mathrm{~m}$ heights $(\mathbf{0 , 5 6 - 3 , 5 1 G W h / y e a r )}$ [3]. The following graph illustrates the comparison between the energy production of the wind concept and the current energy consumption in Droevendaal.

\subsection{The biomass concept}

The biomass concept incorporates the cultivation of energy plants (poplars) for the production of bio-energy. In order to determine the total energy production, concerning the biomass concept, is viable to determine the potential biomass 
harvest in the Droevendaal area. The latter regards the number of poplar trees that could possibly be planted, if the entire Droevendaal surface would be available. The following table depicts the potential number of poplar trees, as long as the amount of biomass and the potential energy production of the site.

Table 1: Wind energy content in different heights concerning the Droevendaal area and potential energy production (source: Danish wind industry association) [2].

\begin{tabular}{|c|c|c|c|}
\hline $\begin{array}{c}\text { Height } \\
(\mathrm{m})\end{array}$ & $\begin{array}{c}\text { Wind energy content } \\
\left(\mathrm{KWh} / \mathrm{m}^{2} . \text { year }\right)\end{array}$ & $\begin{array}{c}\text { Total } \\
(\mathrm{KWh} / \text { year })\end{array}$ & $\begin{array}{c}\text { Total } \\
(\mathrm{GWh} / \mathrm{year})\end{array}$ \\
\hline 30 & 711 & 35550000 & 35.55 \\
\hline 50 & 921 & 46050000 & 46.05 \\
\hline 100 & 1268 & 63400000 & 63.4 \\
\hline
\end{tabular}

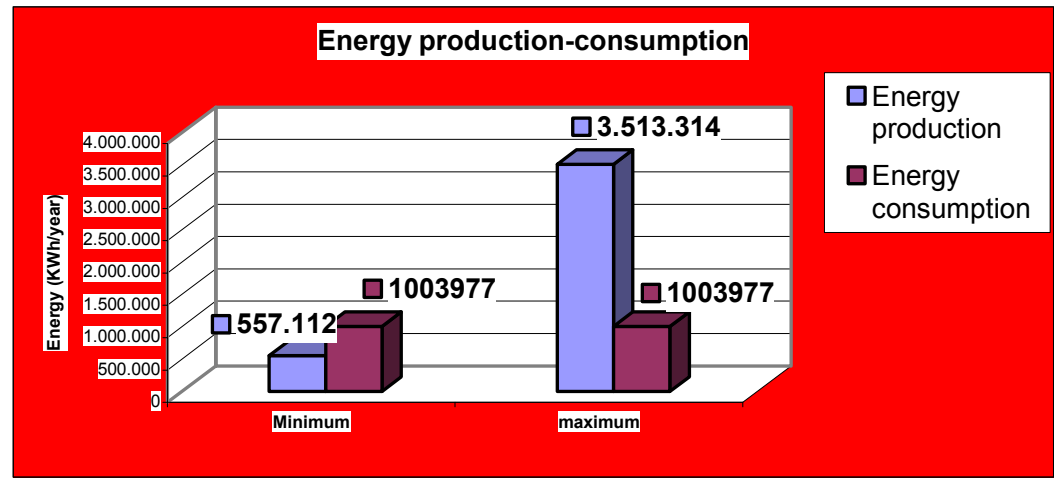

Figure 2: Comparison between the energy production of the wind concept and the energy consumption of the Droevendaal area.

Table 2: $\quad$ Potential biomass and bioenergy production from poplar trees in the Droevendaal area.

\begin{tabular}{|c|c|c|}
\hline Number of poplar trees & $\begin{array}{c}\text { Biomass production } \\
\text { (drytn/year) [4] }\end{array}$ & $\begin{array}{c}\text { Energy production } \\
\text { (KWh/year) }\end{array}$ \\
\hline 50.000 & 60 & 305.556 \\
\hline
\end{tabular}

Moreover, concerning the realistic biomass harvest has to be referred that the available surface in Droevendaal is 3 ha and the maximum number of trees that can be cultivated is 30.000 . Thus, the biomass production will be then 36dryth/year and the energy production will, consequently be about 
200.000KWh/ year. The following graph illustrates the comparison between the energy production of the biomass concept and the current energy consumption in Droevendaal.

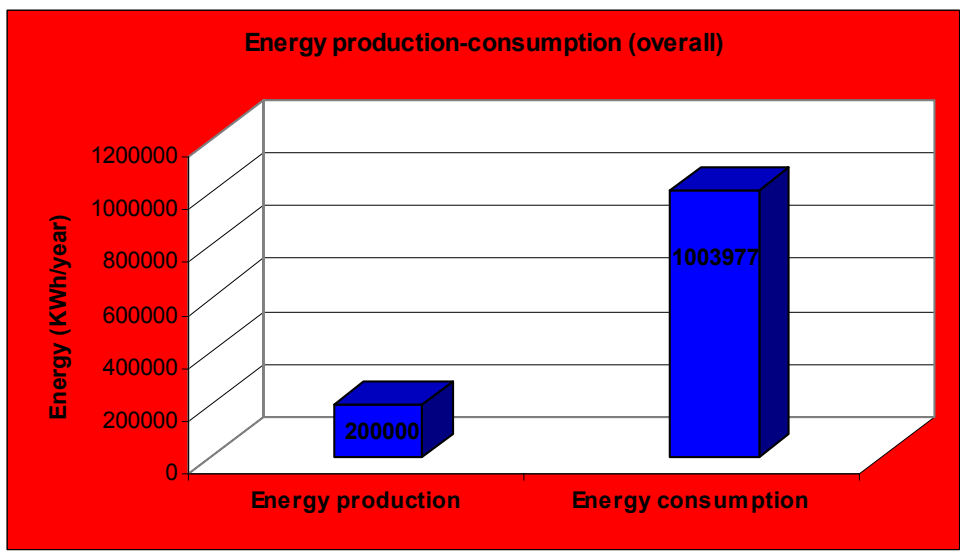

Figure 3: Comparison between the energy production of the wind concept and the energy consumption of the Droevendaal area.

\section{Scenarios}

Our aim, while developing the aforementioned energy harvest concepts, was on the one hand to assess the potential and the actual harvest of each one separately and on the other hand to integrate them in different scenarios. Moreover, these scenarios were ranked and rated in order to give us a more accurate vision on the sustainable nature of their context.

\subsection{Maximum energy production scenario}

The first scenario, which was developed, concerns the maximum energy production. In order to accomplish its purpose, to produce the highest possible amount of energy, almost every available source of energy was used. In particular, the solar PV, the solar thermal, the energy road and the wind energy concepts were used in order to achieve a maximum energy production. The advantage of this scenario is that the energy production is as high as a factor 7 (6.803.626KWh/year) of the energy consumption of the area. The disadvantage of this scenario is that neglects critical issues of social sustainability, as the intervention on the natural local environment and the multifunctionality of land use are.

The following graph illustrates the comparison between the energy production under the context of the present scenario and the energy consumption of the Droevendaal area. 


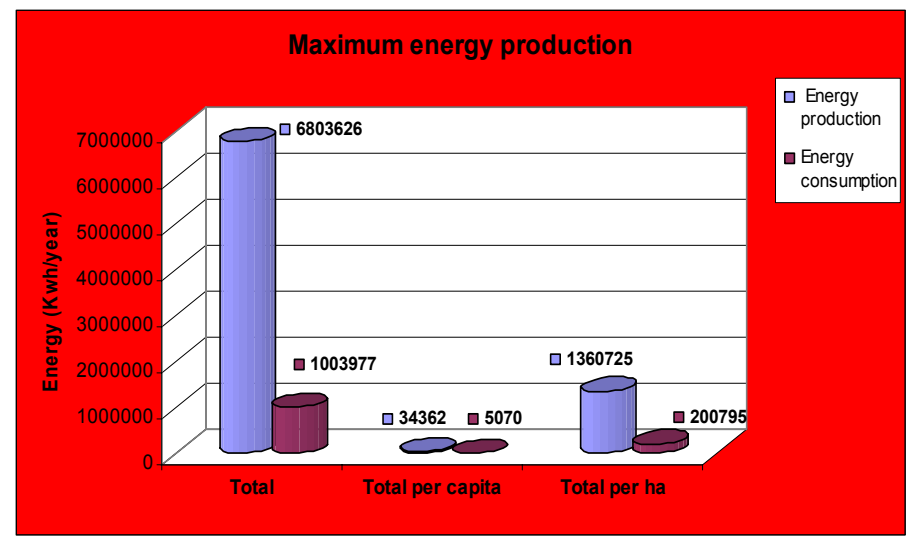

Figure 4: Comparison between the energy production by the proposed maximum energy scenario and the energy consumption in Droevendaal.

\subsection{Social sustainability scenario}

The second scenario concerns the social sustainability in correlation with renewable energy planning and implementation. This scenario presents some essential differences respectively to the first scenario. In fact it keeps the energy production in factor 5 level (4909236KWh/year), higher than the energy consumption in Droevendaal, while it takes under consideration social issues of the area, such as aesthetical and land use. The result is the creation of an essential balance between technical and social sustainability issues.

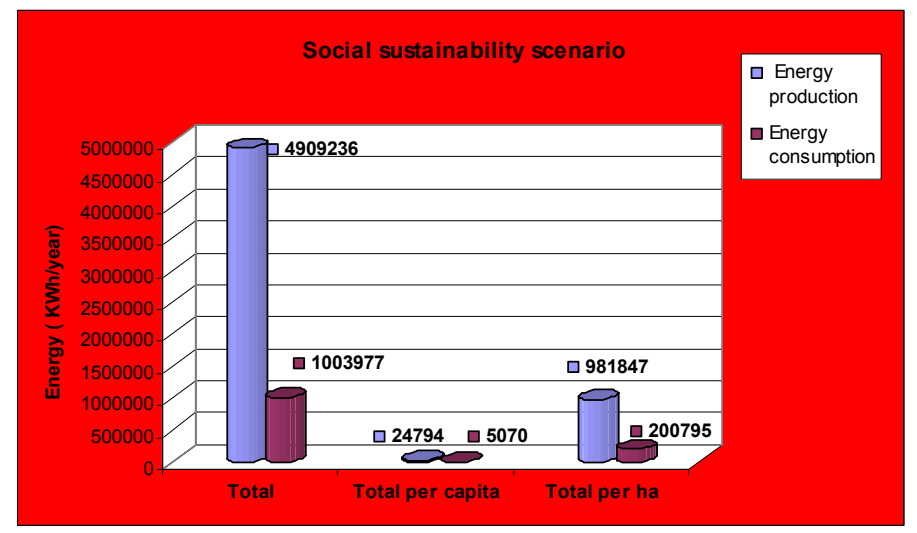

Figure 5: Comparison between the energy production by the proposed social sustainability scenario and the energy consumption in Droevendaal. 


\subsection{Cost efficiency scenario}

The third scenario, which was developed, concerns cost efficiency issues. In other words, this latter scenario was developed in order to achieve the highest possible production of energy in the lowest possible cost. Thus, it could be characterized also as a market-oriented scenario. In fact the amount of energy production is as high as a factor4 (4.589.372KWh/year) of the energy consumption in Droevendaal. Simultaneously, it presents the lowest cost, 1.783.558€, in comparison with the other scenarios, while it keeps issues of social sustainability in a quite high level. The sources of energy that were used under the context of this scenario are the wind energy and the solar thermal energy because they present the higher efficiency in the lowest cost. The following graph illustrates the comparison between the energy production under the context of the present scenario and the energy consumption of the Droevendaal area.

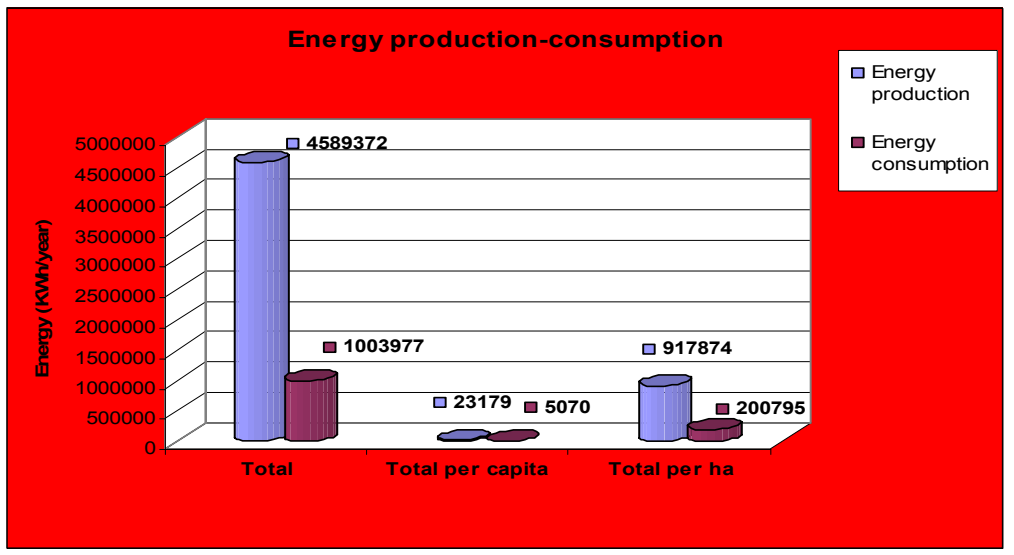

Figure 6: Comparison between the energy production by the proposed social sustainability scenario and the energy consumption in Droevendaal.

\section{Scenarios ranking}

The scenarios ranking and rating has been performed according to the following criteria

- The energy production

- The level of energy autonomy of the area under the proposed scenarios

- The environmental performance of the proposed scenarios

- The energy production costs of the proposed scenarios

- The level of land use of the proposed scenario

- The degradation level of the local landscape aesthetics

In this point it would be essential to summarize the data, concerning each of the proposed scenarios in order to facilitate the reader's observation. Thus the following table presents the basic characteristics of each scenario. 
Table 3: Illustration of the technical and spatial characteristics, concerning each of the proposed scenarios.

\begin{tabular}{|l|l|l|l|l|l|}
\hline Slements & $\begin{array}{l}\text { Energy } \\
\text { production } \\
\text { (KWh/year) }\end{array}$ & $\begin{array}{l}\text { Level of } \\
\text { energy } \\
\text { autonomy }\end{array}$ & $\begin{array}{c}\text { Cost } \\
(€)\end{array}$ & $\begin{array}{c}\text { Land use } \\
\left(\mathrm{m}^{2}\right)\end{array}$ & $\begin{array}{l}\text { Degradation of local } \\
\text { landscape aesthetics }\end{array}$ \\
\hline Scenario 1 & 6803626 & Factor 7 & 13868489 & 25145 & $\begin{array}{l}\text { The solar panels do not } \\
\text { allow any } \\
\text { multifunctional land use } \\
\text { and additionally create a } \\
\text { black coloured } \\
\text { landscape, which is not } \\
\text { aesthetically acceptable }\end{array}$ \\
\hline Scenario 2 & 4909236 & Factor 5 & 1909814 & 20000 & $\begin{array}{l}\text { The poplar trees and the } \\
\text { wind turbine allow the } \\
\text { multifunctionality of the } \\
\text { landscape and do not } \\
\text { intervene much in the } \\
\text { local environment's } \\
\text { Besides the fact that 1ha } \\
\text { of area is free of to be } \\
\text { transformed in a } \\
\text { playground or any other } \\
\text { desired social structure } \\
\text { enforces the aesthetic of } \\
\text { the local environment }\end{array}$ \\
\hline Scenario 3 & 4589372 & Factor 4 & 1783558 & Negligible & $\begin{array}{l}\text { There is only a wind } \\
\text { turbine that intervenes to } \\
\text { the local natural } \\
\text { environment. The rest of } \\
\text { the surface is free for } \\
\text { different use according } \\
\text { to the residents desire }\end{array}$ \\
\hline
\end{tabular}

Taking under consideration the aforementioned criteria, the ranking of the three suggested scenarios had the following results, as these are illustrated in the following figure.

As it can be observed in the graph above, the cost efficient scenario seems to be the scenario that presents the best performance $(38 \%)$, while the maximum energy production scenario presents the lowest performance (25\%). This difference mainly occurs because of differences in cost, in land use and in interventions concerning the landscape aesthetics, issues very important for a globe overview of sustainable energy production.

\section{Discussion}

During this study, was attempted an approach to Droevendaal residential area as an energy producer, rather than an energy consumer. The results that have been drawn show transparently that the site has not only the potential to cover its own energy needs without any external energy supply, but also the potential to produce much more energy (factor4-factor7), respectively to the three scenarios 


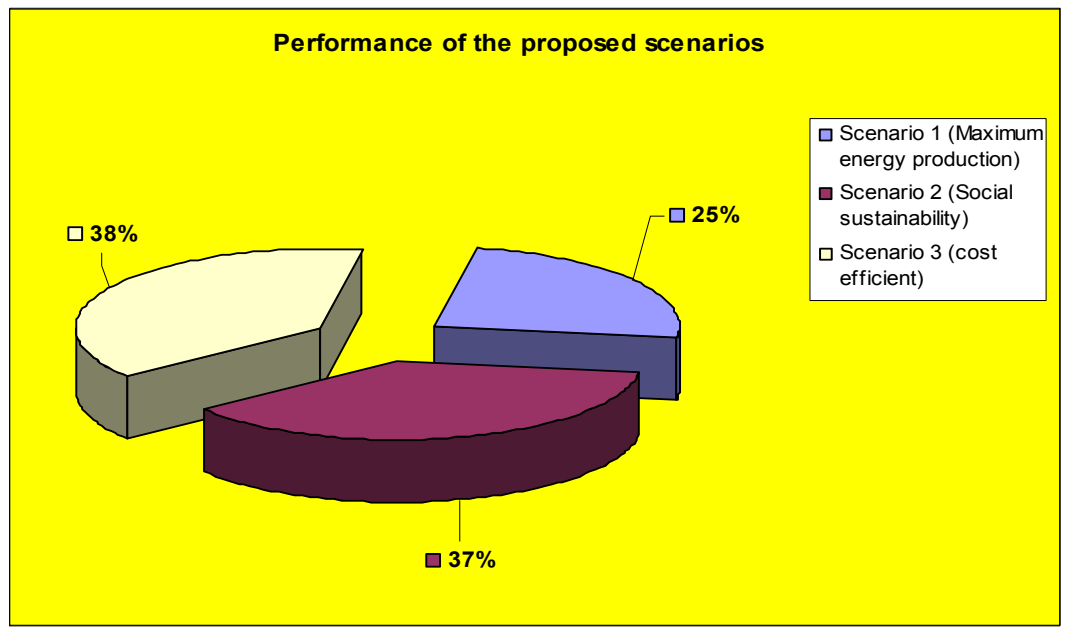

Figure 7: $\quad$ Performance of the proposed scenarios according to the selected criteria.

of cost efficiency, maximum energy production and social sustainability, which have been developed during previous sections.

Furthermore, as issues that were addressed above proved, an optimum renewable energy planning, as a part of a wider scope towards more sustainable societies, is rather a matter of balancing different elements (environment, economics, energy production etc.), than a matter of one-dimensional targets. Thus, energy planning cannot be treated as an isolated part of the rural-urban planning, but as an integrated special part of it. Moreover, it should be stated in this point that Droevendaal site consists of a small and rather simple system and this approach was made in the paths defined by this system. Thus, in order to assess the viability of this approach with respect to larger systems, further research should be performed in order to adjust and adapt the developed indicators in more complex environments.

\section{References}

[1] EU Commission, Directorate General Joint Research Centre; Institute for Environment \& Sustainability http://re.jrc.ec.europa.eu/pvgis/solradframe. php?en\&europe

[2] Danish Wind Industry association http://www.windpower.org/en/tour/wres/ enrspeed.htm

[3] Danish Wind Industry association http://www.windpower.org/en/tour/wres/ pow/index.htm

[4] Holger Rogner Hans et al, Energy resources (chapter 5). World energy assessment: Energy and the challenge of sustainability, UN publications: Geneva \& New York p.160, 2000 http://stone.undp.org/undpweb/seed/wea/ pdfs/ chapter5.pdf 